\title{
Puerperal sepsis leading to bilateral fulminating purulent endophthalmitis with tenonitis
}

\author{
M. R. JAIN AND H. R. SHARMA
}

From the Department of Ophthalmology, 7.L.N. Medical College, Ajmer, and R.N.T. Medical College, Udaipur, India

Only one case of bilateral purulent endophthalmitis as a sequel to puerperal fever has been reported (Dayal, Sood, Prakash, and Bhatia, I97I); the condition has been known unilaterally since the time of Jüngken ( 1836 ), although even that appears to be rare (Ring, I 927 ; Brown, I934; Bonnet, Chauviré, and Bonnet, I950; Duke-Elder and Perkins, I966).

\section{Case report}

A 40-year-old woman, was admitted to hospital on February 16 , 1972, with the complaint of sudden loss of vision 4 days before, leading to complete blindness within 48 hours. The visual loss was associated with increasing neuralgia and was followed by extreme chemosis of the lids and conjunctiva with mucopurulent discharge.

HISTORY

The patient had aborted a 5-months-old foetus under unhygenic conditions attended by a quack 8 days previously, and a high temperature with chills and rigor and a copious vaginal discharge had developed 48 hours later.

She had had eight full-term normal deliveries, and there was no apparent reason for this first abortion.

GENERAL EXAMINATION

The patient was well built and moderately nourished, but anaemic. There was no lymphadenopathy, and no evidence of meningitis, or of any affection of the central nervous or cardiovascular systems. Blood pressure $100 / 60$; pulse rate $1 \mathrm{i} 6 / \mathrm{min}$; ; temperature $102{ }^{\circ} \mathrm{F}$.

OPHTHALMOLOGICAL EXAMINATION

The upper and lower eye lids and bulbar and palpebral conjunctivae showed moderate congestion with severe chemosis causing eversion of the lower lids and covering most of the cornea (Fig. I).

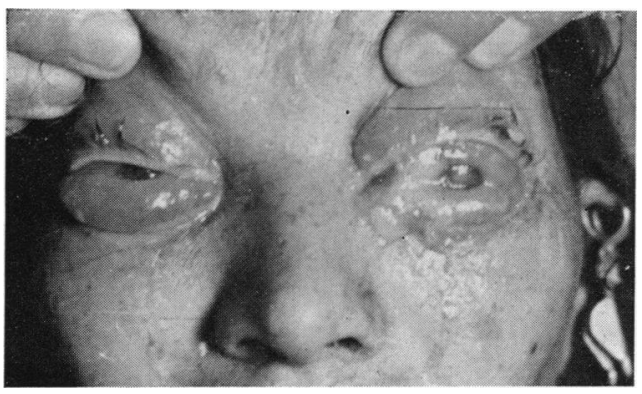

FIG. I Bilateral fulminating endophthalmitis 
Both corneae were slightly hazy and the anterior chambers were full of thick fluffy exudates tinged with blood. The pupil and lens could hardly be identified. The ocular tension was below normal. There was about 25 per cent. restriction of ocular movements in all directions. Corneal sensitivity was almost unaffected.

L. ABORATORY INVESTIGATIONS

The only abnormalities were a raised erythrocyte sedimentation rate and a low haemoglobin level. Staphylococcus albus was cultured from the aqueous humour and Staph. albus and B. coli from the foul vaginal discharge.

TRE A TMENT

Intensive therapy included an intravenous broad-spectrum antibiotic (Rolitetracycline), oral oxyphenbutazone, and subconjunctival injections of chloramphenicol, mydricaine, and corticosteroids.

PROGRESS

The fever subsided within 3 days and the chemosis within ro days. The exudates also decreased, but hyphaema persisted for 20 days. The corneae became brighter, but the pupils appeared to be small and irregular with complete annular synechiae and the lenses were covered with a veil of exudates. The ocular tension was further reduced and the eyes showed a tendency to shrink (Fig. 2). Moreover, during the course of treatment, the left eye appeared to develop a divergent squint and a scleral abscess on the upper medial side (Fig. 3). The patient did not recover her sight and the eyes progressed to phthisis bulbi.
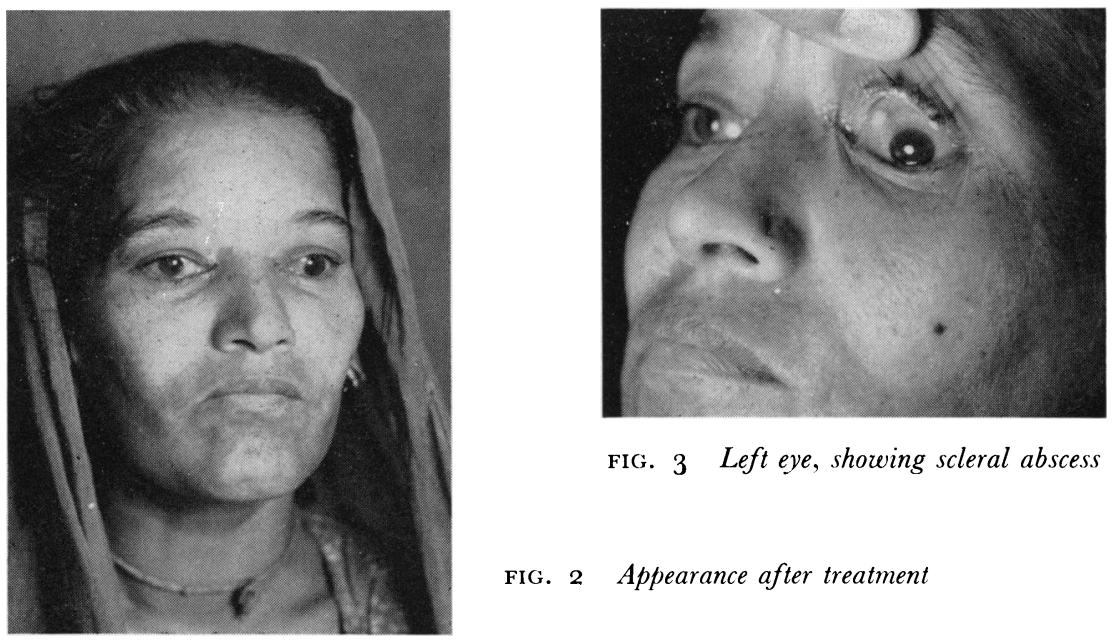

FIG. 3 Left eye, showing scleral abscess

FIG. 2 Appearance after treatment

\section{Summary}

A case is reported in which endophthalmitis secondary to puerperal septicaemia led to complete blindness.

\section{References}

Bonnet, P., Chauviré, E., and Bonnet, J. L. (1950) Bull. Soc. Ophtal. Fr., 3, io6 BROWN, A. L. (1934) Arch. Ophthal. (Chicago), 12, 730

Dayal, y., Sood, n. N., PRAkash, P., and Bhatia, I. (1971) Orient. Arch. Ophthal., 9, 258 DUKe-ELder, s., and PERKins, E. s. (1966) "System of Ophthalmology", vol. 9. Kimpton, London Jüngken, J. C. (1836) “Die Lehre von den Augenkrankheiten”, 2nd ed. Schüppel, Berlin RING, G. O. (1927) Trans. Amer. ophthal. Soc., 25, 93 